\title{
O Lugar de Outras Tipologias Musicais no Ensino Artístico Especializado da Música em Portugal
}

\section{The Place of Other Musical Types in the Specialized Artistic Teaching of Music in Portugal}

\author{
Sidónio Manuel da Costa Oliveira, António José Pacheco Ribeiro \\ Universidade do Minho
}

\begin{abstract}
Resumo
O objetivo deste artigo é contribuir para uma projeção futura do Ensino Artístico Especializado (EAE) da Música em Portugal e permitir a reflexão crítica sobre o seu funcionamento até aos nossos dias. Neste sentido, irá realizar-se um estudo de caso múltiplo para explorar as tipologias musicais que se lecionam em 3 conservatórios públicos do EAE, utilizando como método de pesquisa o inquérito por questionário e a entrevista para descrever os resultados obtidos na investigação de campo. Procura-se, assim, saber se há ou não outras tipologias musicais nos conservatórios públicos do EAE da música em Portugal, e responder, ou não, a uma lacuna que se pensa acompanhar o currículo e programas nas escolas de música.

Palavras-chave: ensino artístico especializado, música, tipologias musicais, programas, diversidade.
\end{abstract}

\begin{abstract}
The purpose of this article is contributing to a future projection of the Specialized Artistic Education of Music (SAE) in Portugal and allow a critical reflection on its operation up to the present day. Thus, a multiple case study will be carried out to explore the musical typologies taught in 3 public music conservatories of the Specialized Artistic Education, using as a research method the questionnaire survey and the interview to describe the results obtained in the research field. It is therefore sought to know whether or not there are other types of music in the public conservatories of the SAE of Music in Portugal, and whether or not to respond to a gap that is thought to accompany the curricula and programs in music schools. Keywords: specialized artistic education, music, musical typologies, programs, diversity.
\end{abstract}

O dogma de centrar as aprendizagens da música no ensino clássico da cultura musical ocidental (Grout e Palisca, 2007), mantém um conservadorismo nas escolas. Há uma segmentarização dos géneros musicais no ensino vocacional: o sobre apreço da música erudita (Castelo-Branco, 2010), conhecida também como música clássica (Kennedy e Kennedy, 2013); e a subestimação da música popular, definida como um termo amplo que inclui o Blues, o Jazz, o Rock e as suas versões comerciais, a música Folclórica, entre muitos outros tipos musicais (Grout e Palisca, 2007). Em todas escolas de música do ensino especializado/vocacional e do ensino profissional há a sobrevalorização da música ligada à cultural erudita (Ferreira e Vieira, 2013).

Uma situação recorrente, mesmo depois das grandes reformas estruturais do ensino em Portugal com a Lei n. ${ }^{\circ}$ $5 / 73$, de 25 de julho, e com a reforma do ensino artístico promovida pelo Decreto-Lei n. ${ }^{\circ} 310 / 83$, de 1 de julho, que reestrutura o ensino da música, organizando a sua institucionalização desde o ensino básico até ao ensino superior do país, remodelando os processos e ramos educacionais, os diferentes cursos e regimes de frequência das aulas, e o seu público alvo.

Transformações importantes para o ensino da música, que ao longo das suas sucessivas remodelações e reestruturações, ainda assenta em incertezas caracterizando todo este subsistema de ensino (Pacheco, 2008), levantando questões quanto aos modelos pedagógicos e os processos de ensino e aprendizagem neles envolvidos actualmente Apesar do fortalecimento educativo do ensino obrigatório em Portugal, e com a reforço do estudo das artes nas escolas públicas com a Portaria n. ${ }^{\circ} 691 / 2009$, de 25 de junho, alterada pela Portaria n. ${ }^{\circ}$ 267/2011, de 15 de setembro, salientam-se na legislação portuguesa a Portaria n. ${ }^{\circ}$ 225/2012, de 30 de julho, e a Portaria n. ${ }^{\circ}$ 243-B/2012, de 13 de agosto, que reforçam em ambos os preâmbulos, o Decreto-Lei n. ${ }^{\circ}$ 139/2012, de 5 de julho, que institui os fundamentos orientadores da organização e da gestão dos currículos do ensino básico, reforçando, entre outros muitos aspetos, a autonomia pedagógica e organizativa das escolas do EAE. Observa-se o reforço do ensino para todos, de uma escola inclusiva nas escolas artísticas públicas, privadas e cooperativas, que passaram a ter a decisões sobre os seus currículos e programas, ainda se constata que não há mudanças nem nos repertórios, nem nos métodos e processos de ensino e aprendizagem em Portugal (Ferreira e Vieira, 2013).

Actualmente, há inúmeras teorias sobre o ensino e a aprendizagem da música, e nomes incontornáveis da pedagogia musical que dão hoje uma nova dimensão à Educação Musical. São o caso da Audiação de Gordon (2000), os trabalhos desenvolvidos pelas investigações e 
estudos sobre as aprendizagens informais e o ensino não formal de Green (2005, 2008), do processo de Apreciação musical de Swanwick (1979, 2003, 2006), da Teoria espiral do desenvolvimento musical de Swanwick e Tillman (1986), e da Audição musical activa de Wuytack e Palheiros (1995).

Todos estes autores assinalam a mudança sobre o ensino actual, com transformações importantes a nível social, cultural e estético, ampliando o conceito de ensino musical (Vasconcelos, 2007), renovando a educação, visando não só o desenvolvimento de conteúdos rítmicos e tonais, mas também o desenvolvimento das competências intelectuais, pessoais e sociais dos alunos.

De facto, é importante assinalar as várias e diferentes maneiras em que as pessoas realmente se relacionam e identificam com a música (Swanwick, 1979), e os professores necessitam de encontrar um método para que os alunos participem de uma forma mais activa nas aulas.

Inúmeras questões se levantam quanto à finalidade educativa da música, e para dar respostas às exigências do século XXI será necessário transformar os currículos e programas institucionalizados há muito. É necessário dar importância ao público alvo e ao seu gosto musical, independentemente do seu futuro profissional (Pacheco, 2008).

É preciso saber se há ou não outras tipologias musicais nos conservatórios em Portugal, e desmistificar, ou não, que o ensino da música do EAE estará unicamente ligado à música erudita. Se assim é, as instituições de ensino vocacional de música, necessitam de redefinir os currículos e programas escolares existentes, sendo imprescindível o espaço para se poder explorar, escolher e decidir as peças (Swanwick, 2003), que os professores podem ensinar, mas especialmente a que os alunos querem aprender.

Muitas investigações, por exemplo, nos países Escandinavos, nos Estados Unidos da América, no Canadá e no Reino Unido, reportam que os currículos dos Conservatórios, Academias e instituições de Ensino Superior de Música já têm estabelecidos nos seus programas música popular (denominada também como pop music), jazz, música tradicional (denominada também como folk music) e world music (Anttila, 2010); (Dyndahl e Nielsen, 2014); (Hill, 2009); (Lubet, 2009); (Peters, 2016); (Wu, 2012).

É crucial dar importância às questões da multiculturalidade e pluralidade musical nos dias que correm (Swanwick, 2003), e saber se há lugar para outras tipologias musicais no EAE em Portugal é uma pergunta pertinente face às condições de acompanhar os requisitos educacionais do séc. XXI, da escola inclusiva, da escola para todos.

\section{Método}

A metodologia de investigação deste projecto será baseada no Estudo de Caso Múltiplo, porque em conformidade com Yin (2015), o Estudo de Caso leva-nos a entender o "como" funciona um fenómeno social, fazendo a sua descrição extensa e profunda, ou o "por quê" sobre o funcionamento desse fenómeno social, explicando a sua circunstância presente. Como ainda não há estudos sobre este assunto, esta investigação é exploratória, sendo a sua base de conhecimentos vaga e limitada, com poucos ou nenhum estudo relevante sobre este caso específico, sendo a sua abordagem nova (Creswell, 2009).

Neste sentido, explorar um único caso não será relevante para a importância do tema a ser investigado, e para validar os resultados o uso de "fontes múltiplas de evidência" (Yin, 2015, p. 50) criam linhas convergentes de investigação na recolha de dados, o que permite ainda estabelecer uma cadeia de evidências significativas para conceber "generalizações analíticas" (idem, p.72)

De facto, a investigação poderia se submeter simplesmente a um único caso, contudo, em conformidade com Yin (2015), projectar um Estudo de Caso Múltiplo irá "predizer resultados similares (uma replicação literal)" (p.60), permitindo tirar conclusões e generalizações que suportam com maior confiabilidade as descobertas da investigação, minimizando "os erros e as parcialidades do estudo" (p. 51).

Se os casos apresentarem resultados similares torna-se substancial na replicação directa das conclusões que o estudo possa apresentar, sobre as suas peculiaridades que podem estar representadas nos conservatórios de ensino público de música, reduzindo "as críticas e o ceticismo" (pp. 67-68) para as teorias ou preposições teóricas que irão ser generalizadas às restantes instituições de EAE de música em Portugal.

Partindo desta base conceptual, saber se há ou não outras tipologias musicais no EAE em Portugal remete-nos para inúmeras perguntas que poderiam alargar a investigação e perder o foco central do seu tema principal.

Para o efeito, serão selecionadas um conjunto de 3 escolas públicas que se inserem nesta tipologia formando assim uma amostra não probabilística intencional, escolhida para uma finalidade específica (Cohen, Manion, e Morrison, 2007), para representar a realidade educativa do EAE público em Portugal. Um dos critérios para a triagem da amostra passa por escolher um conservatório da região norte (Escola Artística do Conservatório de Música Calouste Gulbenkian, de Braga), outro da região centro (Conservatório de Música de Coimbra) e por último um da região sul (Escola Artística de Música do Conservatório Nacional, de Lisboa) de Portugal continental.

Esta pesquisa de Estudo de Caso Múltiplo será caracterizada e realizada em 3 escolas públicas do EAE da música em Portugal, sendo utilizado, em conformidade com Yin (2015), como fonte de evidência a entrevista por questionário com perguntas abertas e fechadas (Johnson e Christensen, 2008) aos professores e aos alunos, e entrevistas aos directores, que neles estão inseridos, para poder responder eficazmente à questão do estudo, e as descobertas baseadas nos perfis observados possam ter fontes múltiplas de evidência para "confirmar ou negar as expectativas originais" (Yin, 2015, p. 170) de haver ou não outras tipologias musicais que não a música erudita nos conservatórios públicos de ensino de música no continente português; saber se os professores escolhem ou não as tipologias musicais em função dos programas estipulados, e se os alunos 
sugerem os seus gostos e preferências para a escolha dos géneros musicais que aprendem.

Este Estudo de Caso Múltiplo decorrerá no ano lectivo 2017/2018, e em conformidade com Neuman (2014), com o intuito de responder à problemática apresentada, o instrumento de recolha de dados que mais se adequa à investigação é o inquérito por questionário e a entrevista. Assim, seguindo as componentes sugeridas por Yin (2015), depois de a principal questão estar formulada, e examinando o tema de estudo, serão levantadas as consequentes preposições para o questionário, apurando as seguintes unidades de análise: o tipo musical que se lecionam nos conservatórios; quem seleciona os programas; a opinião dos professores sobre as tipologias que lecionam; a preferência ou gosto dos alunos em relação ao que aprendem nos conservatórios.

Os dados recolhidos na pesquisa pelo questionário com perguntas abertas e fechadas e pelas entrevistas irão gerar estatísticas mistas de análise (qualitativa e quantitativa), como uma estratégia sequencial exploratória, que usa os dados e resultados quantitativos para assistir, e reforçar a interpretação das descobertas qualitativas do questionário (Creswell, 2009) aplicado à amostra não probabilística intencional (Cohen, Manion, e Morrison, 2007) deste Estudo de Caso Múltiplo.

Atendendo às questões éticas que possam surgir, todos os participantes terão que assinar uma declaração de consentimento e responsabilidade pelas respostas que fornecem, para que estas sejam uma descrição real e verdadeira do assunto estudado (Johnson e Christensen, 2008), sendo a identidade de cada director, professor e aluno, confidencial e anónima. Também será elaborado um pedido aos encarregados de educação para que autorizem os seus educandos a participar na investigação.

Para representar a validade e fiabilidade da investigação e dos seus resultados, a sua evidência estará baseada nas respostas obtidas nos questionários e nas entrevistas realizados à amostra, e, o uso de "fontes múltiplas de evidência" (Yin, 2015, p. 50) criam linhas convergentes de investigação na recolha de dados. Estas linhas convergentes de investigação, permitem ainda estabelecer uma cadeia de evidências constituída pelo grupo específico de participantes (Norming Group) (Johnson e Christensen, 2008), como são os directores, professores e alunos das escolas do EAE de música, tendo esta investigação uma abordagem utilitarista (idem) para que, depois de se apresentarem os resultados, se possa fazer o debate das práticas educativas que vigoram no ensino da música no âmbito vocacional.

Antes de se aplicar os questionários e as entrevistas para a investigação, será realizado um teste piloto em uma escola do EAE da Música em Portugal para testar a sua funcionalidade e encontrar pontos ou perguntas que possam ser confusas e equivocas para a sua interpretação e implementação no projecto de investigação.

\section{Resultados e discussão}

A importância deste projeto não se pode centrar em um único conservatório público do EAE de música, e para ter uma ideia mais precisa da realidade nacional sobre as tipologias que são ministradas nos programas de música, dependeria do conhecimento de toda a realidade educativa do EAE público, neste caso, estudar as 10 instituições de ensino público de música em Portugal (Escola Artística do Conservatório de Música Calouste Gulbenkian, de Braga; ESA - Conservatório de Música do Porto; Escola Artística do Conservatório de Música Calouste Gulbenkian, de Aveiro; Conservatório de Música de Coimbra; Escola Artística de Música do Conservatório Nacional, de Lisboa; Instituto gregoriano de Lisboa; Agrupamento de Escola Via-longa, de Vila Franca de Xira; Escola Básica e Secundária da Bemposta, de Portimão; Conservatório - Escola Profissional das Artes da Madeira/Eng. Luís Peter Clode, de Funchal; Conservatório Regional de Ponta Delgada).

Uma investigação desta dimensão não é impossível, mas as questões temporais e orçamentais para a realização de uma tese de doutoramento, viabilizam a realização de um projecto conciso e bem definido, que estude no mínimo um caso ou no máximo 3 instituições do EAE de Música para se tornar viável e fundamente a questão principal da pesquisa. Neste sentido, o presente projeto irá se fundamentar no Estudo de Caso Múltiplo, que utilizará como instrumento de recolha de dados o inquérito por questionário e a entrevista, utilizando para o efeito uma metodologia mista investigação.

As apreciações que possam surgir deste trabalho de investigação surgirão da exploração, descrição, análise e interpretação das diferentes fontes de dados recolhidos pelos questionários e pelas entrevistas, de forma a enriquecer o processo de ensino de música em Portugal. Assim sendo, os resultados obtidos serão apresentados e divulgados em revistas científicas da área da Educação e da Música, e posteriormente num relatório escrito incluído na tese de Doutoramento. Estes artigos e relatório devem descrever e enquadrar a problemática, e dar resposta à questão de investigação através da apresentação dos dados obtidos, da sua interpretação e dos respectivos resultados conclusivos a que estes conduziram.

O projeto de investigação deverá, ainda, contribuir para o conhecimento da realidade musical do país e, consequentemente, possibilitar a adopção de estratégias e medidas político-culturais que consolidem os projectos educativos das escolas intervenientes, reforcem a sua autonomia pedagógica e se insiram efetivamente nas suas comunidades locais/regionais.

\section{Referencias}

Anttila, M. (Novembro de 2010). Problems with school music in Finland. British Journal of Music Education, 27(3), 241-253.

http://dx.doi.org/10.1017/S0265051710000215

Castelo-Branco, S. (2010). Enciclopédia da Música em Portugal no Século XX L-P (Vol. 3). Lisboa: Temas e Debates.

Cohen, L., Manion, L., \& Morrison, K. (2007). Research Methods in Education ( $6^{\mathbf{a}}$ ed.). London: RoutledgeFalmer. 
Creswell, J. W. (2009). Research Design: Qualitative, Quantitative, and Mixed Methods Approach ( $3^{\mathrm{a}}$ ed.). USA: Sage Publications.

Dyndahl, P., \& Nielsen, S. G. (2014). Shifting authenticities in Scandinavian music education. Music Education Research, 16(1), 105-118. http://dx.doi.org/10.1080/14613808.2013.847075

Ferreira, S., \& Vieira, M. H. (2013). Práticas formais e informais do ensino da música: Questionando a dicotomia. Revista de Educação Artística, 87-97.

Gordon, E. E. (2000). Teoria de aprendizagem musical. Lisboa: Fundação Calouste Gulbenkian.

Green, L. (2005). How Popular Musicians Learn: A Way Ahead for Music Education ( $3^{\mathrm{a}}$ ed.). Hants, England: Ashgate.

Green, L. (2008). Music, informal learning and the school: a new classroom Pedagogy. Hampshire, England: Ashgate.

Grout, D. J. \& Palisca, C. V. (2007). História da Música Ocidental. Lisboa: Gradiva.

Hill, J. (2009). The Influence of Conservatory Folk Music Programmes: The Sibelius Academy in Comparative Context. Ethnomusicology Forum, 18(2), 207-241. http://dx.doi.org/10.1080/17411910903141882

Johnson, B., \& Christensen, L. (2008). Educational Research: Quantitative, Qualitative, and Mixed Approaches ( $3^{\mathrm{a}}$ ed.). London: SAGE.

Kennedy, M., \& Kennedy, J. B. (2013). The Oxford Dictionary of Music. (T. Rutherford-Johnson, Ed.) Oxford: Oxford University Press.

Lubet, A. (2009). The inclusion of music/the music of inclusion. International Journal of Inclusive Education, 13(7), 727-739. http://dx.doi.org/10.1080/13603110903046010

Neuman, W. L. (2014). Social Research Methods: Qualitative and Quantitative Approaches ( $7^{\mathrm{a}}$ ed.). Harlow: Pearson Education Limited.

Pacheco, A. (2008). O Ensino da Música em Regime Articulado no Conservatório do Vale do Sousa: Função Vocacional ou Genérica? Braga: Instituto de Estudos da Criança da Universidade do Minho.

Peters, G. (Junho de 2016). Do Students See Themselves in the Music Curriculum? A Project to Encourage Inclusion. Music Educators Journal, 102(4), 22-29. http://dx.doi.org/10.1177/0027432116644330

Swanwick, K. (1979). A basis for music education. London and New York : Routledge.

Swanwick, K. (2003). Ensinando musica musicalmente. (A. Oliveira, \& C. Tourinho, Trads.) São Paulo: Moderna.

Swanwick, K. (2006). Música, pensamiento y educación (3. ${ }^{\text {a }}$ ed.). Madrid: Ediciones Morata.

Swanwick, K., \& Tillman, J. (Junho de 1986). The sequence of musical development: a study of children's composition. British Journal of Music Education, 3(3), 306-339. http://dx.doi.org/10.1017/S0265051700000814

Vasconcelos, A. Â. (Setembro/Dezembro de 2007). A música no $1 .^{\circ}$ Ciclo de Ensino Básico: o estado, a sociedade, a escola e a criança. Revista de Educação Musical, 128-129, pp. 5-15.
Wu, S. (2012). Reflecting on the implications, problems and possibilities raised by the entrance of 'world musics' in music education. British Journal of Music Education, 29(3), 303-316. https://doi.org/10.1017/S026505171200037X

Wyutack, J., \& Palheiros, G. B. (1995). Audição musical activa - livro do professor. Porto: Associação Wyutack de Pedagogia Musical.

Yin, R. K. (2015). Estudo de Caso: planejamento e métodos ( $5^{\mathrm{a}}$ ed.). (C. M. Herrera, Trad.) Porto Alegre: Bookman. 